\title{
Clinicohistopathological Correlation in Leprosy
}

\author{
Mathur MC, Ghimire RBK, Shrestha P, Kedia SK
}

Department of Dermatology

College of Medical Sciences

Bharatpur, Chitwan, Nepal

Corresponding Author

Ghimire RBK

Department of Dermatology

College of Medical Sciences

Bharatpur, Chitwan, Nepal

Email:

Citation

Mathur MC, Ghimire RBK, Shrestha P, Kedia SK. Clinicohistopathological Correlation in Leprosy Kathmandu Univ Med J 2011;36(4):248-51.

\begin{abstract}
\section{Background}

Leprosy is a chronic, infectious disease caused by Mycobacterium leprae. It is classified into five groups based on clinical, histological, microbiological and immunological criteria (Ridley \& Jopling Classification). However, a great variation has been observed in the interpretation of histopathological examination ok skin biopsies and clinical presentation of the disease.
\end{abstract}

\section{Objective}

To correlate clinical diagnosis with histopathological diagnosis of leprosy patients in Nepal.

\section{Methods}

A retrospective hospital-based study was conducted among patients with all clinical types of leprosy, classified as per the Ridley-Jopling classification. Skin biopsies were taken from active lesions in all patients and were stained with Hematoxylin \& Eosin stain and modified Fite-Ferraco stain for identification of Mycobacterium leprae. The histopathological findings were compared with clinical diagnoses.

\section{Results}

A total 156 patients were studied, out of which 84 (53.8\%) males and 72 (46.1\%) females between 8 and 86 years of age. The majority of patients 33 (23.57\%) were in the age group of 21-30 years and least affected was children below 10 years $1(0.007 \%)$. Overall coincidence of clinical and histopathological diagnoses of classification was seen in 115 cases (80.4\%). The maximum correlation (95.2\%) was noted in LL patients ( $p$ value 0.000049 ) followed by BT(89.74\%), TT (73.2\%), BL(72.4\%), BB(64.7\%).

\section{Conclusion}

Leprosy still continues to be one of the common infectious disease in Nepal and skin biopsy is a useful tool in confirming the clinical diagnosis of leprosy as well as for the therapeutic guide.

\section{KEY WORDS}

Mycobacterium leprae, Leprosy, histopathology

\section{INTRODUCTION}

Leprosy is a chronic, infectious disease caused by Mycobacterium leprae. The disease mainly affects peripheral nervous system, the skin, and certain other tissues such as the reticulo-endothelial system, bones and joints, mucous membranes, eyes, testes, muscles, adrenals, etc. ${ }^{1}$ The disease presents itself in different clinico-pathological forms, depending on the immune status of the host. ${ }^{2}$

Leprosy continues to be an important public health problem in most parts of Africa, Latin America, Asia including Nepal. ${ }^{3}$ On 19 January 2010, the government of Nepal declared the elimination of leprosy, after achieving a prevalence rate of 0.89 per 10,000 population. ${ }^{4}$ However, still remains to be a common clinical condition among the medical visits, necessitates a periodic revival of our knowledge about the disease.

The spectrum of disease in leprosy has been characterized in a number of clinico-immunopathological classification systems, the most widely used being the Ridley-Jopling classification. Ridley \& Jopling have proposed the classification of leprosy into five groups as Tuberculoid (TT) (fig 2), Borderline tuberculoid (BT), Mid-borderline (BB), Borderline lepromatous ( $B L$ ) and Lepromatous (LL) (fig 1). with strict criteria for definition, this system have become 
Table 1. Clinical aspects of Ridley-Jopling Classification of Leprosy.

\begin{tabular}{|c|c|c|c|c|c|}
\hline \multirow[t]{2}{*}{ Observation or test } & \multicolumn{5}{|l|}{ Type of leprosy } \\
\hline & TT & BT & BB & BL & LL \\
\hline Number of lesions & Single usually & Single or few & Several & Many & Very many \\
\hline Size of lesions & Variable & Variable & Variable & Variable & Small \\
\hline Surface of lesions & $\begin{array}{l}\text { Very dry, sometimes } \\
\text { scaly }\end{array}$ & Dry & Slightly shiny & Shiny & Shiny \\
\hline $\begin{array}{l}\text { Sensation in lesions } \\
\text { (not face) }\end{array}$ & Absent & $\begin{array}{l}\text { Moderately or mark- } \\
\text { edly diminished }\end{array}$ & $\begin{array}{l}\text { Slightly or moderately } \\
\text { diminished }\end{array}$ & Slightly diminished & $\begin{array}{l}\text { Not affected or minimally } \\
\text { affected }\end{array}$ \\
\hline Hair growth in lesions & Absent & Markedly diminished & $\begin{array}{l}\text { Moderately dimin- } \\
\text { ished }\end{array}$ & Slightly diminished & Not affected \\
\hline AFB in lesions & Nil & Nil or scanty & Moderate numbers & Many & Very many (plus globi) \\
\hline $\begin{array}{l}\text { AFB in nasal scraping } \\
\text { or in nose blows }\end{array}$ & Nil & Nil & Nil & Usually nil & Very many (plus globi) \\
\hline Lepromin test & Strongly positive $(+++)$ & $\begin{array}{l}\text { Weakly positive (+ } \\
\text { or }++ \text { ) }\end{array}$ & Negative & Negative & Negative \\
\hline
\end{tabular}

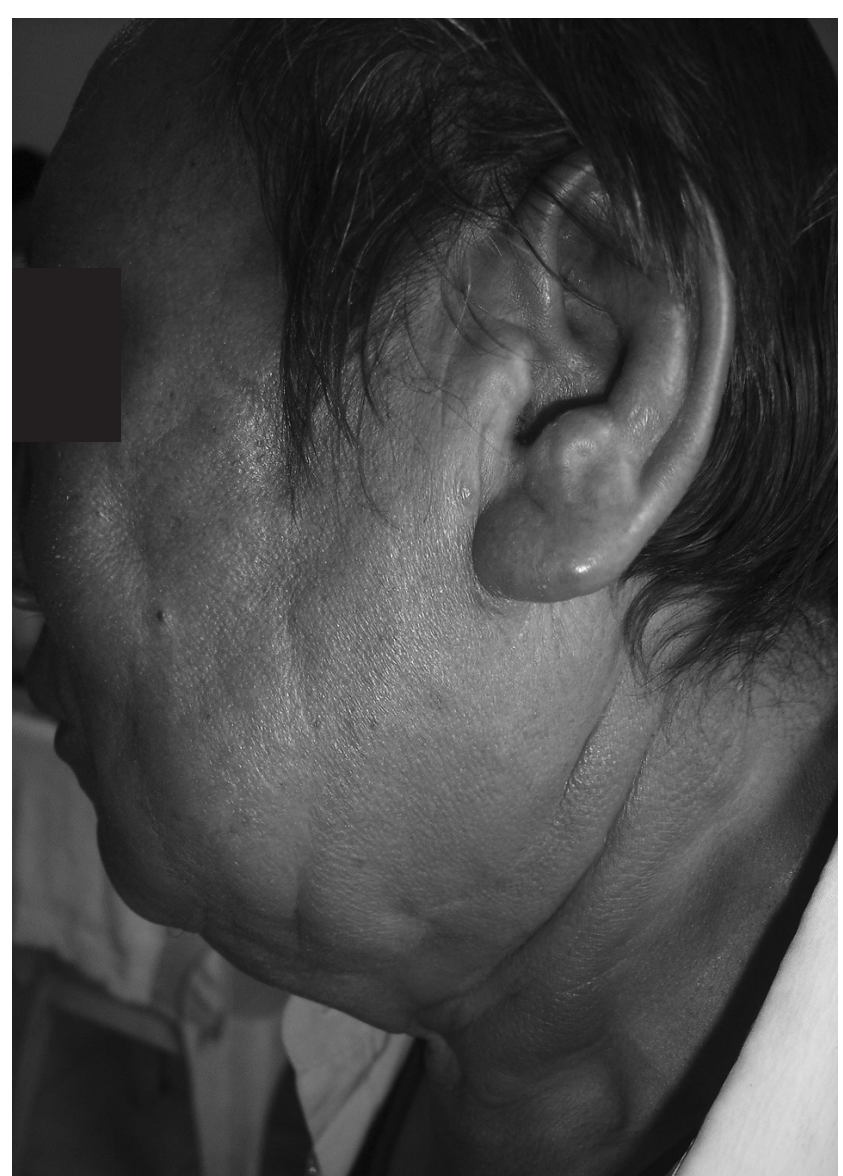

Figure 1. Lepromatous leprosy(LL) with infiltration of earlobes, eyebrows.

generally accepted worldwide and is recommended (table 1). ${ }^{5}$ However, a great variation has been observed in the interpretation of both the histopathological examination and pathological reports in view of clinical presentations of the disease.

An extensive pubmed search did not reveal any such article correlating clinical and histological types of Leprosy from Nepal. The study was undertaken to correlate different clinical types of leprosy and histopathology of skin biopsies.

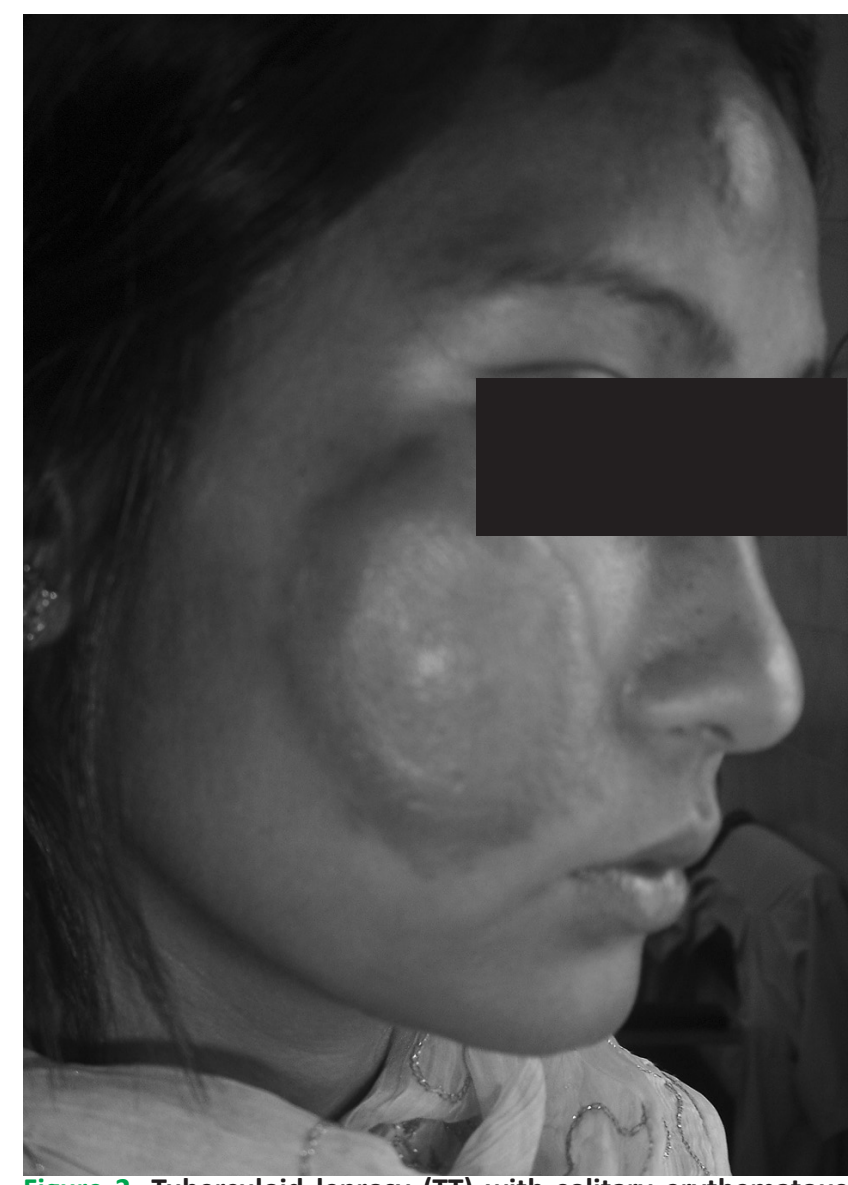

Figure 2. Tuberculoid leprosy (TT) with solitary erythematous infiltrated plaque over right cheek.

\section{METHODS}

A retrospective hospital-based study was conducted in 156 patients of leprosy, who visited Dermatology outpatient of College of Medical Sciences, Bharatpur, Chitwan between January 2007 to August 2011. All patients with different clinical spectrum of leprosy, were included in the study and graded as per the Ridley-Jopling classification into TT, BT, $\mathrm{BB}, \mathrm{BL}$ and LL. Patients already treated with anti-leprosy medications in any time earlier were excluded. Skin biopsies were taken from active lesions in all patients after taking 


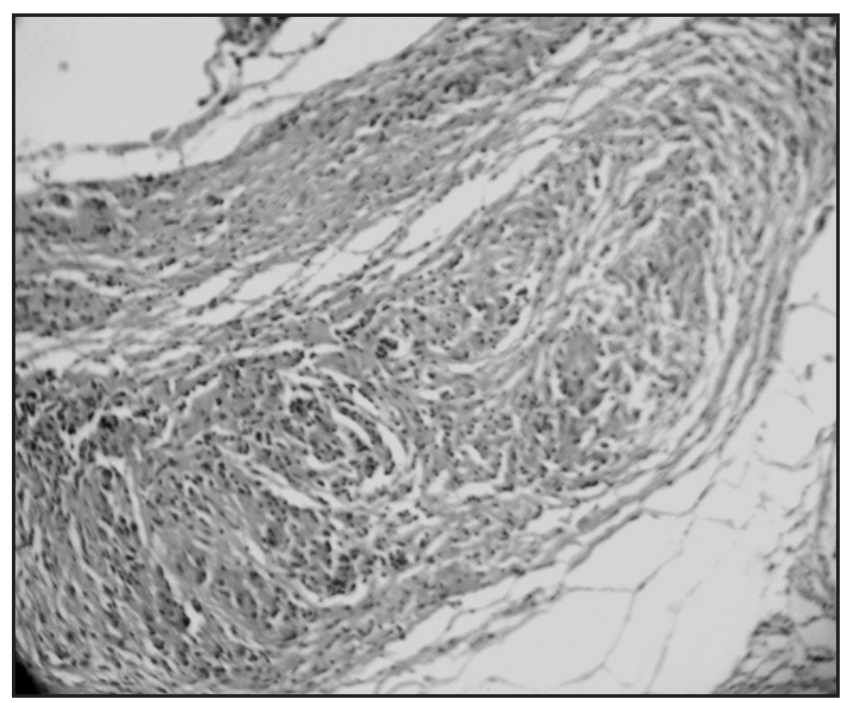

Figure 3. Histopathology of skin biopsy (H\&E stain-40x) showing compact granuloma along neurovascular bundle with dense peripheral lymphocytes (TT).

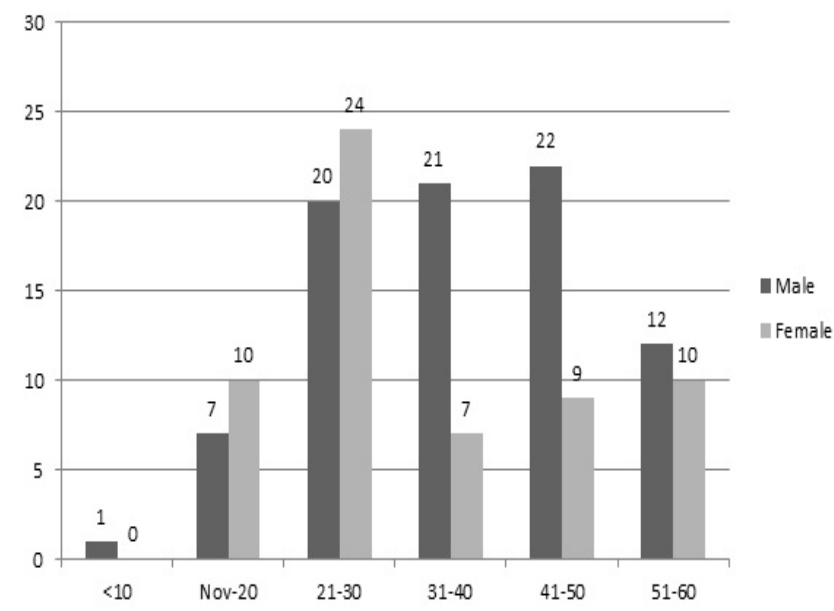

Figure 5. Age-sex distribution in leprosy patients.

informed consent and approval from institutional ethical committee and biopsies were processed as per standard protocol in Department of Pathology. They were stained by Hematoxylin \& Eosin stain (fig 3) and modified Fite-Ferraco stain (fig 4) for identification of Mycobacterium leprae. However, immune status of the patients could not be assessed. Statistical analysis was done using SPSS software version 16.0 .

\section{RESULTS}

The study group consisted of total 156 patients, out of which $84(53.8 \%)$ males and 72 (46.1\%) females between 8 and 86 years of age. The majority of patients $33(23.57 \%)$ were in the age group of 21-30 years and least affected was children below 10 years, $1(0.007 \%)$.(Fig 5)

The overall coincidence of diagnosis of clinical diagnosis with histopathologies of biopsies were seen in 115 cases (80.4\%). The maximum correlation $(95.2 \%)$ was noted in LL patients ( $p$ value 0.000049 ) followed by BT(89.74\%), TT

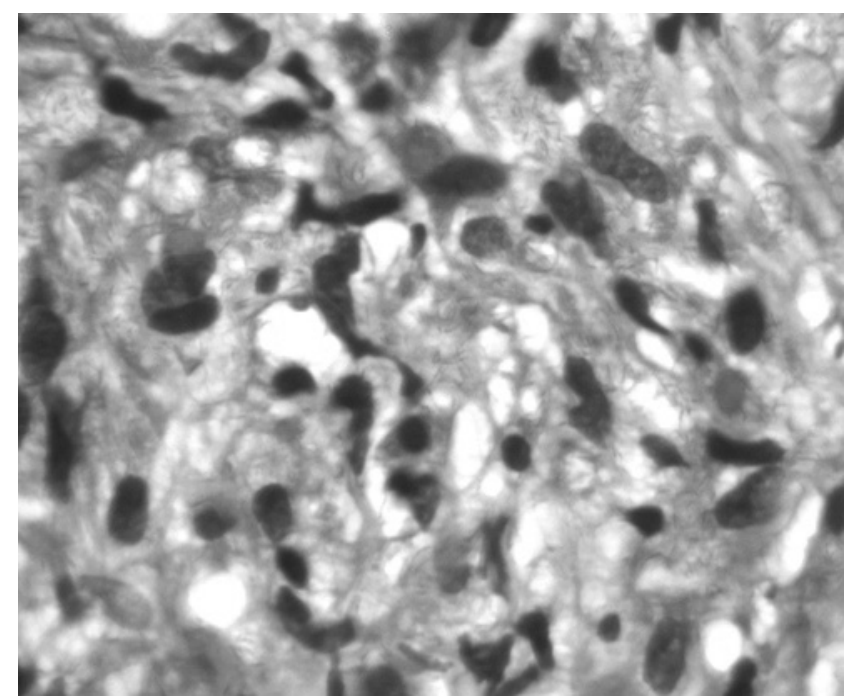

Figure 4. Histopathology (Fite-Ferraco stain- 100x) showing solidly stained and fragmented bacilli, Virchow cells(LL)..

(73.2\%),BL(72.4\%), BB(64.7\%) with p values shown in table 2. Although almost similar distribution of cases was seen in clinical and histopathological classification, number of IL cases were more by histopathological classification than by clinical classification.

The consistency of findings are summarized in with crosstabulation.(Table 2)

\section{DISCUSSION}

Leprosy, a chronic granulomatous infectious disease endemic in south-east asia. Clinical presentation varies from few to widespread lesions. Histopathology of skin lesions varies from compact granulomas to diffuse infiltration of dermis, which largely depend upon the immune status of the patient and may not be in agreement with the clinical diagnosis.however, clinical and histopathological disparities are seen due to varied clinical manifestations even in established leprosy, so individual lesions may differ microbiologically and histologically.

The histopathological findings from our study showed agreement with clinical diagnosis in $115(80.4 \%)$ cases. Ridley and Jopling found agreement between clinical and histological types in 56 (68.3\%) out of 82 cases patients. Similarly, Bhusan et al. showed a concordance of $74.47 \%$, Kar et al 70\%, Jerath and Desai 68.5\%, Moorthy et al $62.63 \%$, Sharma et al. $53.44 \%$, between the histological and clinical diagnoses. ${ }^{6-10}$

The patients in our study were 84 (53.8\%) males and 72 (46.1\%) females between 8 and 86 years of age. The majority of patients $33(23.57 \%)$ were in the age group of 21-30 years and least affected was children below 10 years $1(0.007 \%)$ as shown in table 1 . A similar study conducted by Moorthy et al. from India, among 372 leprosy patients showed 242 (65.05\%) males and 130 (34.95\%) females between three and 86 years of age. The majority of patients 
Table 2. Cross tabulation showing findings of clinical diagnoses with histological diagnoses.

\begin{tabular}{|c|c|c|c|c|c|c|c|c|c|}
\hline \multirow[b]{2}{*}{ Classification } & \multirow[b]{2}{*}{ Clinical Diagnosis } & \multicolumn{5}{|c|}{ Histological Diagnosis } & \multirow[b]{2}{*}{ Indeterminate } & \multirow[b]{2}{*}{ Chronic Inflammation } & \multirow[b]{2}{*}{$p$-values } \\
\hline & & TT & BT & BB & BL & LL & & & \\
\hline TT & 56 & 41 & 1 & 0 & 1 & 0 & 7 & 6 & 0.0005 \\
\hline BT & 38 & 1 & 35 & 0 & 0 & 0 & 0 & 2 & 0.0000 \\
\hline BB & 11 & 0 & 0 & 6 & 0 & 0 & 0 & 5 & 0.2200 \\
\hline LL & 29 & 1 & 2 & 1 & 21 & 1 & 0 & 3 & 0.0170 \\
\hline Indeterminate & 21 & 0 & 1 & 0 & 0 & 20 & 0 & 0 & 0.0000 \\
\hline Chronic Inflammation & 1 & 0 & 0 & 0 & 0 & 0 & 1 & 0 & 0.0000 \\
\hline Total & 156 & 43 & 39 & 7 & 22 & 21 & 8 & 16 & \\
\hline
\end{tabular}

were in the age group of $20-29$ years $(20.70 \%)$ and least affected were children below 9 years $(6.45 \%){ }^{9}$

The present study showed correlation between clinical and histological diagnosis in 115 cases (80.4\%). The maximum correlation (95.2\%) was seen in LL patients followed by $\mathrm{BT}(89.74 \%), \mathrm{TT}(73.2 \%), \mathrm{BL}(72.4 \%), \mathrm{BB}(64.7 \%)$. In study by Moorthy et al., while correlating the histopathological diagnosis with clinical diagnosis, maximum correlation (80\%) was noted in LL patients followed by $\mathrm{BL}(70 \%)$, $\mathrm{BT}(66.54 \%), \mathrm{BB}(50 \%), \mathrm{TT}(46.15 \%)$ and it was very poor in IL $(20 \%) .{ }^{8}$ Sharma et al. showed maximum parity in LL (75.86\%), followed by BL (58.82\%), BT (53.01\%), TT (47.37\%), and least in BB cases (37.35\%). Indeterminate leprosy cases showed $100 \%$ clinicopathological concordance. ${ }^{10}$ Kar et al. observed highest parity in stable poles, i.e. TT (87.5\%) and LL (71.4\%), followed by IL (81.2\%), BT (60.9\%), BB (54.5\%) and $\mathrm{BL}(53.8 \%){ }^{6}$ In another study by Bhusan et al. reported concordance was maximum in LL (12) and TT (3) cases with $100 \%$ agreement, and was 69 (83.13\%) in BT, $6(50 \%)$ in BB, and 15 (65.22\%) in BL cases. Similarly, Kalla et al. in a study of 736 patients observed highest parity in LL and TT group (76.7\% and $75.6 \%)$, respectively, followed by BT $(44.2 \%)$, BL (43.7\%) and BB (37.0\%). ${ }^{11}$ Jerath et al conducted study in 130 cases and found TT (74.5\%), BT (64.7\%), BB (53.8\%) and $\mathrm{BL}(28.5 \%), \mathrm{LL}(61.5 \%)$ and indeterminate leprosy $(88.8 \%) .^{7}$ In a study conducted in Brazil, skin histology correlated with clinical assessment in $19(68 \%)$ patients in BL, BT patients $11(44 \%)$ and LL patients 4 (57\%) patients only. ${ }^{12}$

Considering the data of present study and other comparative studies, we may state that maximum correlation is seen with LL as it shows a fixed histopathology. However, in early cases of tuberculoid (TT) and indeterminate (IL) forms of disease, histopathology shows ambiguity. Thus histopathology should be viewed in relation to clinical diagnosis as revealed in our study.

Therefore, skin biopsies should be taken from the representative lesions in order to establish the diagnosis as an adjunct to clinical diagnosis and fulfilling the criteria for classifying the disease spectrum, which directly influences the proper treatment and eradication of the disease.

\section{CONCLUSION}

Leprosy, though reported to be eliminated, still continues to be one of the common infectious diseases in Nepal and necessitates revival of our knowledge regarding the disease. Skin biopsy is a useful tool in confirming the clinical diagnosis of leprosy as well as for the therapeutic guide.

\section{REFERENCES}

1. ShettyVP, RP DoshiRP. Detection and Classification of Leprosy :Future Needs and Strategies. Indian J Lepr 2008; 80:139-47.

2. Abulafia J, Vignale RA. Leprosy: Pathogenesis updated. Int I Dermatol 1999; 38:321-34.

3. Jain MC. Leprosy Scenario in Nepal. J Nepal Med Assoc 2008; 47:25963

4. Government of Nepal- Ministry of Health \& Population, Department of Health sciences, Leprosy control division. [Available from http:// dohs.gov.np/?q=node/47].

5. Jopling WH, Mc Dougall. The disease. In: Jopling WH, Mc Dougall. (Authors) Handbook of leprosy. Fifth edition. CBS Publishers and distributors (India)2008;10-53.

6. Bhushan P, Sardana K, Koranne RV et al. Diagnosing multibacillary leprosy: A comparative evaluation of diagnostic accuracy of slitskin smear, bacterial index of granuloma and WHO operational classification. Indian J Dermatol Ven Lepr 2008; 74: 322-6.

7. Kar PK, Arora PN. Clinicopathological study of macular lesions in leprosy. Indian J Lepr 1994;66:435-41.

8. Jerath VP, Desai SR. Diversities in clinical and histopathological classification of Leprosy. Lepr India 1982; 54:30.

9. Moorthy BN, Kumar P, Chatura KR et al. Histopathological correlation of skin biopsies in leprosy. IJDVL 2001;67:299-301

10. Sharma A, Sharma RK, K C Goswsami KC, Bardwaj S. ClinicoHistopathological Correlation in Leprosy. JK Science 2008 ;10:120-4.

11. Kalla G, Salodkar A, Kachhawa D. Clinical and histopathological correlation in leprosy. Int J Lepr 2000;68:184-5.

12. Barbosa AA Jr., Jambeiro J, Cirqueira JSO, Silva TC. Retrospective histopathological classification of 1,108skin biopsies from patients clinically suspected of having leprosy from Bahia, Northeast Brazil. Revista da Sociedade Brasileira de Medicina Tropical 1998;31:533-7. 